\title{
Potato stalk buds compression characteristic test
}

\author{
Ziwei Gong ${ }^{1}$, Wei Sun ${ }^{1}$, Jianmin $\mathrm{Wu}^{1}$, Fene Wang ${ }^{1}$, Weijun Guo ${ }^{2}$ \\ ${ }^{1}$ Engineering College, Gansu Agriculture University \\ ${ }^{2}$ School of Mechanical Engineering, Longdong University
}

Keywords: Potato buds; test; compression strength; maximum compressive strain.

\begin{abstract}
In order to research the mechanics characteristics of potato stalk buds, Experimental determination of the potato stalk buds $25 \mathrm{~d}$ bud age compression feature parameters, and the compression strength and the maximum compressive strain characteristics of the single factor analysis of variance test. The results show that the potato stalk bud at the top, middle and base of compression strength are $0.43 \sim 0.81 \mathrm{MPa}, 0.81 \sim 1.21 \mathrm{MPa}$ and $0.91 \sim 1.60 \mathrm{MPa}$ respectively, the biggest compressive strain were $0.11 \sim 0.27,0.15 \sim 0.31$ and $0.17 \sim 0.40$ respectively. It integrally manifested as compression strength and the maximum compressive strain increases from the top to the base of the potato buds, and the difference of the compression strength and the maximum compressive strain at the top and base of buds is remarkable.
\end{abstract}

\section{Introduction}

The plastic mulching technology, it can improve the growth environment of crops, significantly increase the yield of the potatoes $(2,8,13,14)$, it is one of the arid and semi-arid region of spread of an important technology of high yield and stable yield. But the effect of making seedlings was burning to die easily, low germination rate, it need the artificial seedlings, not only time-consuming work, but low working efficiency. In order to this problem, cover with a thin layer of soil just above on the seed row, rely on the soil on the membranes of the gravity and potato bud shoot their natural upward force broke ground rupture in emergence $(10,15,6,5)$. At present, the research focuses on the technology of potato growth and soil ecological effect, and the rupture mechanism of shoot few research reports. Therefore, studies the mechanical properties in the process of shoot emergence to reveal the rupture mechanism and suitable membrane covering the variety of planting is important. Scholars at home and abroad, mainly for wheat, rice, maize, the main food crop stalks mechanics characteristics of a lot of research, and obtained many achievements $(1,3,4,7,9,11,12,16,17,18)$. In these studies, the mechanical properties and damage mechanism of potato stalk buds studies are rare. Therefore, in this paper, through experimental study on potato stalk buds mechanical properties, the purpose is to breed new varieties, to further improve the bearing capacity of the potato stalk buds to provide certain reference basis.

\section{Test materials and methods}

\subsection{Test equipment}

The experiment using Shenzhen SANS CMT2502 type microcomputer control electronic universal testing machine, the machine can be displayed real-time dynamic force in the process of test, displacement, deformation, loading speed and test curve. After the test, you can output the complete test reports and test curve. This machine is the maximum test force of $100 \mathrm{~N}$, the value error is plus or minus $1 \%$ of force display and the value error is plus or minus $0.5 \%$ of displacement shown.

\subsection{Test materials}

As shown in figure 1 of potato stalk buds, the experimental materials come from Gansu Province Academy of Agricultural Sciences field, In May 10, 2013 the film covering the soil for planting, the June 5, 2013 sampling, select start top film length in 130-150mm of buds. Three varieties are the Atlantic, the Xindaping and the Longshu No.3 respectively. Sample by the internodes interception, 
the interception of 3 section from top to bottom, top, middle and base respectively, intercept length is about 2 times the diameter.

\subsection{Test methods}

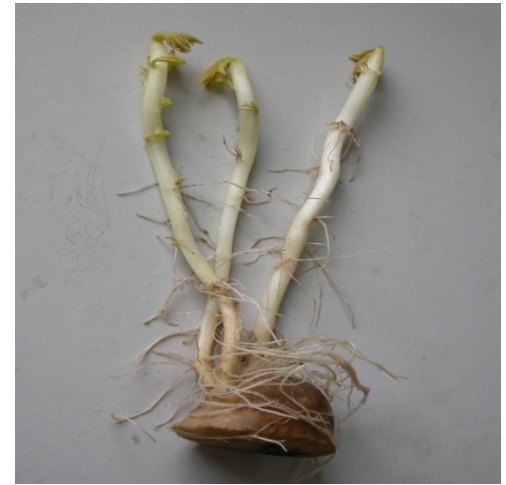

Fig.1 The potato shoot

The test was carried out in Gansu Agricultural University Laboratory for material mechanics from June 30th to July 15th in 2013, using the inner wall for 10mm's of fine drawing seamless steel tube is made from 5mm depth mould, Two ends of the sample into a mould. In order to study the rupture of membrane the changes before and after of the buds compression characteristics, and the sample is comparable to that of, the sample classification. Before the start of the experiment, the diameter lengths were measured by vernier caliper. The sample is placed in the workbench of the test machine, with $2 \mathrm{~mm} / \mathrm{min}$ speed test to exert pressure for the sample.

\section{The results and analysis}

\subsection{The potato buds mechanics performance}

Figure 2 is the potato buds (Xindaping) from the top to the base of compression force displacement curve. The figure shows that buds the compression failure process roughly experienced three stages (Take the top of buds, for example): (1) The approximate linear elastic stage, the approximate linear relationship between stress and strain, that is, the sigma is proportional to the epsilon, the materials obey Hooke's law, the elastic modulus E=3.04MPa. (2) The yield stage, when the stress is greater than $0.693 \mathrm{MPa}$, the continue to load the pressure reaches $24.1 \mathrm{~N}$, stress reaches maximum, sigma Max is $0.730 \mathrm{MPa}$, The stress and strain is no longer linear relationship, but is still the elastic deformation, the curve peak for the ultimate strength. (3) The deformation failure stage, when the stress reaches sigma Max, the buds began to rupture.

The potato buds has high strength and good elasticity, the fracture failure took place in the cross section within the stalk buds (12). The following is the different varieties of potato buds 25d bud age, for the compression strength and the maximum compressive strain is analyzed, the results are shown in the table 1.

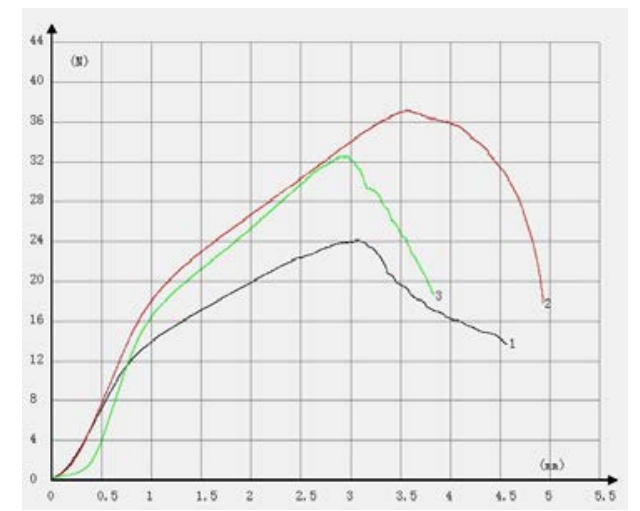

Fig.2 Curve of compression force-displacement of Potato buds 
Note: the compression materials for Xindaping; 1-3 represent the buds at the top, middle and base respectively, the top to the base of the buds diameter are 6.5, 6.0, and $5.0 \mathrm{~mm}$ respectively, compressed length are 2 times the diameter of the sample, the loading speed are $2 \mathrm{~mm} / \mathrm{min}$.

Table 1 Analysis compression strength and the maximum compressive strain of different varieties potato stalk buds

\begin{tabular}{|c|c|c|c|c|c|c|}
\hline \multirow[b]{2}{*}{$\begin{array}{l}\text { Internode } \\
\text { position }\end{array}$} & \multicolumn{2}{|c|}{ The Atlantic } & \multicolumn{2}{|c|}{ Xindaping } & \multicolumn{2}{|c|}{ Longshu No.3 } \\
\hline & $\begin{array}{c}\text { The } \\
\text { compression } \\
\text { strength }\end{array}$ & $\begin{array}{c}\text { The biggest } \\
\text { compressive } \\
\text { strain }\end{array}$ & $\begin{array}{c}\text { The } \\
\text { compression } \\
\text { strength }\end{array}$ & $\begin{array}{c}\text { The biggest } \\
\text { compressive } \\
\text { strain }\end{array}$ & $\begin{array}{c}\text { The } \\
\text { compression } \\
\text { strength }\end{array}$ & $\begin{array}{c}\text { The } \\
\text { biggest } \\
\text { compress } \\
\text { ive strain }\end{array}$ \\
\hline The top & $0.7770 \pm 0.1510^{C}$ & $0.2040 \pm 0.0450^{b}$ & $0.6857 \pm 0.0750^{C}$ & $0.1720 \pm 0.0473$ & $0.5500 \pm 0.0613^{\mathrm{C}}$ & $\begin{array}{c}0.1600 \pm 0 \\
.0428^{\mathrm{b}}\end{array}$ \\
\hline The middle & $1.0880 \pm \frac{\mathrm{b}}{\mathrm{b}} 0.2526$ & $0.2520 \pm 0.0686^{\mathrm{a}}$ & $0.9771 \pm \underset{\mathrm{b}}{ \pm 0.1321}$ & $0.2070 \pm \frac{\mathrm{b}}{\mathrm{b}} \mathrm{0.0514}$ & $0.9160 \pm \underset{\mathrm{b}}{0.1137}$ & $\begin{array}{c}0.2586 \pm 0 \\
.0596^{\mathrm{a}}\end{array}$ \\
\hline The base & $1.4480 \pm 0.2100^{\mathrm{a}}$ & $0.2920 \pm 0.0426^{\mathrm{a}}$ & $1.3385 \pm 0.2096^{\mathrm{a}}$ & $0.2690 \pm 0.0722^{\mathrm{a}}$ & $1.3700 \pm 0.1429^{\mathrm{a}}$ & $\begin{array}{c}0.3043 \pm 0 \\
.0264^{\mathrm{a}}\end{array}$ \\
\hline
\end{tabular}

The table shows that the potato buds different internodes of compression strength and the maximum compressive strain differences, the Atlantic buds from top to the base of the compression strength were $0.7770 \mathrm{MPa}, 1.0880 \mathrm{MPa}, 1.4480 \mathrm{MPa}$ respectively, the maximum compressive strain were $0.2040,0.2520,0.2920$ respectively; Xindaping buds from top to the base of the compression strength of $0.6857 \mathrm{MPa}, 0.9771 \mathrm{MPa}, 1.3385 \mathrm{MPa}$ respectively, the maximum compressive strain were $0.1720,0.2070,0.2690$ respectively; Longshu No.3 buds from top to the base of the compression strength of $0.5500 \mathrm{MPa}, 0.9160 \mathrm{MPa}, 1.3700 \mathrm{MPa}$ respectively, the maximum compressive strain were $0.1600,0.2586,0.3043$ respectively. it integrally manifested as performance of compression strength and the maximum compressive strain from the top to the base of the increase, the buds the same internodes of the compression strength the maximum of Atlantic, the second of Xindaping, the minimum of Longshu No.3, the top and base of the compression strength and the maximum compressive strain difference significant, we found the top and base of compression strength and the central significant difference, the maximum compressive strain difference was not significant, That is characterized the middle of the maximum compressive strain of the Atlantic and at the top and base no significant difference, Xindaping the top and the central difference was not significant of the maximum compressive strain, the top and base of the significant difference, Longshu No.3 the central and the base difference was not significant of the maximum compression strain, the central and the top of the significant difference.

Thus it can be seen, the potato stalk buds the compression strength and the maximum compressive strain different as the growth status and the different varieties were changed, namely along with the change of varieties and parts of the growth state of its performance also was changed $(18,12)$.

\section{Conclusion}

The potato stalk buds the top section is measured in experiment can bear the maximum compressive stress is $0.43 \sim 0.81 \mathrm{MPa}$, the failure of compressive strain is $0.11 \sim 0.11$; The middle section can bear maximum compressive stress is $0.72 \sim 1.21 \mathrm{MPa}$, the failure compressive strain is $0.15 \sim 0.15$; The root section can bear maximum compressive stress is $0.91 \sim 1.60 \mathrm{MPa}$, the failure compressive strain is $0.17 \sim 0.40$.

There are differences in compression strength and maximum strain between the same internodes of different varieties buds and different internodes of the same variety buds under the same buds age condition, it integrally manifested as the compressive strength and the maximum compressive strain 
increase from the top to the base of the buds, the difference of the compressive strength and the maximum strain at the top and the base of buds was significant, the difference of the compressive strength at the top, intermediate section and the base of buds was extremely significant, the difference of the maximum compressive strain was not significant.

\section{References}

[1] C. R. Duan, B. C. Wang and P. Q. Wangm, 2003: Journal of Chongqing University: Natural Science Edition, Vol.26 No.11, p.38.

[2] D. H. Mu and J. X. Li, 2009: Gansu Agricultural Science and Technology No.10, p.60.

[3] F. E. Wang, G. B. Huang, W. J. Guo, F. W. Zhang, J. M. Wu and D. J. Zhao, 2009: Transactions of the Chinese Society for Agricultural Machinery, Vol.40 No.5, p.92.

[4] H. B. Meng and L. J. Han, 2003: Journal of China Agricultural University, Vol.8 No.6, p.38.

[5] L. S. Yang, Z. Y. Xi and L. Li, 2010: Chinese vegetables, No.11, p.47.

[6] M. D. Xu, 2004: China. PatentCNl507773.

[7] Niklas KJ, 1998: Annals of Botany, Vol.81 No.1, p.11.

[8] S. M. Ma and S. B. Li, 1997: Crops Magazine, No.4, p.29.

[9] Schulgasser K, Witztum A, 1997: Annals of Botany, Vol.80 No.1, p.35.

[10]T. S. Li and C. H. Fan, 1998: China. Patent CN1192320.

[11]T. Hu, Q. Y. Jiao and Z. Y. Fu, 2007: Chinese Journal of Applied Mechanics, Vol. 24 No.1, p.279.

[12]W. J. Guo, F. E. Wang and G. B. Huang, 2009: Transactions of the Chinese Society for Agricultural Machinery, Vol.40 No.2, p.123.

[13] Y. P. Gong, G. P. Wang and T. Y. Zhang, 2007: China's Potato, Vol. 21(2007) No.3, p.250.

[14]Y. C. Zheng and Q. F. Yang, 2008: Anhui agricultural science, Vol.36 No.20, p.8462.

[15]Y. Yang, 2002: China. Patent CN1341346.

[16]Z. H. Yuan, B. P. Feng and A. Q. Zhao, 2002: Transactions of the Chinese Society of Agricultural Engineering, Vol.18 No.6, p.30.

[17]Z. Y. Wu, H. W. Gao and J. G. Zhang, 2001: Transactions of the Chinese Society for Agricultural Machinery, Vol.32 No.2, p.38.

[18]Z. X. Zhang, W. F. Chen and Z. Y. Yang, 1999: Journal of Shenyang agricultural university, Vol.30 No.2, p.81. 